\title{
AFFORDANCES E CONSTRUÇÃO DE SENTIDOS NOS AMBIENTES VIRTUAIS DE APRENDIZAGEM
}

\author{
SALVADOR/BA JUNHO/2018 \\ JOSE RENATO GOMES DE OLIVEIRA - UFBA - joserenato.ead@gmail.com \\ Tipo: Investigação Científica (IC) \\ Natureza: Relatório Final de Pesquisa \\ Categoria: Pesquisa e Avaliação \\ Setor Educacional: EDUCAÇÃO SUPERIOR
}

\begin{abstract}
RESUMO
Este trabalho discute o problema com affordances e a construção de sentidos em Ambientes Virtuais de Aprendizagem - AVA, que adaptam o Modular Object-Oriented Dynamic Learning Environment Moodle, tomando-se como referência o ambiente virtual de aprendizagem de uma disciplina a distância de uma universidade baiana. Para tal, esta pesquisa desenvolve o trabalho especificando as categorias Acesso, Permanência e Aprendizagem relacionadas às características dos Ambientes Virtuais de Aprendizagem (AVA) customizados e que são utilizados em cursos de educação superior na modalidade à distância, a partir dos pressupostos teóricos da semiótica social e da análise multimodal de Kress (2010) e Van Leeuwen (2012).
\end{abstract}

Palavras-chave: Ambientes Virtuais de Aprendizagem; Affordances; Design de Interface; Construção de Sentidos

\section{AGRADECIMENTOS}

A DEUS, QUE TEM O DOMÍNIO SOBRE TODAS AS COISAS;

AO PROF. HAENZ GUTIERREZ, MAIS QUE UM ORIENTADOR, UM AMIGO PARA AS HORAS FÁCEIS E TAMBÉM ESPECIALMENTE DIFÍCEIS, QUE SUGERIU O TEMA PARA ESTA PESQUISA, 


\section{INTRODUÇÃO}

Pensar o papel dos Ambientes Virtuais de Aprendizagem - AVA, frente à intermediação e construção do conhecimento acadêmico, por meio da educação on-line, é uma questão que tem nos intrigado e tem sido frequentemente questionada, porém pouco investigada frente à demanda de novos cursos que surgem a cada ano. Existe a necessidade de melhores definições sobre os conceitos e significados relacionados às tecnologias empregadas nas interfaces de plataformas e a integração dos diversos saberes e competências a serem desenvolvidas pelos e nos ambientes virtuais.

Muitas são as atividades que se esperam realizar nos chamados ambientes virtuais de aprendizagem. Dentre elas podemos relacionar a construção do conhecimento; a aprendizagem colaborativa; a interatividade e a troca de saberes. Para cumprimento dessas funções e tarefas dentro dos AVA algumas condições são necessárias, tais como o desenvolvimento da autonomia e a motivação do educando (PETERS, 2003; PRETI, 2005; MOORE e KEARSLEY, 2007; PEIXOTO e CARVALHO, 2013); o estabelecimento da interatividade, afetividade e de comunidades virtuais (MATTAR 2013, PRETTO, 2014); a afiliação tecnológica (PALLOFF e PRATT, 2004; POZO, 2014); e a percepção das affordances e construção de sentidos para o desenvolvimento da aprendizagem (CARVALHO, 2010; PAIVA, 2010; SOUZA, 2011; CARVALHO 2013; SOUZA, 2013).Este último, procuramos investigar neste trabalho.

As vantagensmais comuns que levam as instituições a adotarem a modalidade a distância são: alcance massivo, redução de custos, flexibilidade de tempo e possibilidade de estudos em diversas plataformas, o que garante mobilidade para 0 estudante e professor. Sabemos que muitos estudantes adotam a EaD buscando uma titulação acadêmica, melhoria na carreira profissional e, por sua vez, as Instituições de Ensino Superior - IES, buscam ampliar seu número de ofertas a cada ano, visando obtenção de lucro, no caso das IES privadas.Nos últimos anos tem ocorrido um crescimento maior na oferta de cursos na modalidade EaD por parte destas instituições do que das IES públicas.

A Educação Superior a distância no Brasil, não obstante sua presença desde o final do século passado é muito recente. Apenas em 1995 tivemos o primeiro curso autorizado pelo Ministério da Educaçao - MEC, ofertado pela Universidade Federal do Mato Grosso - UFMT, que se realizouatravés de diversas parcerias visando a formação de professores da rede pública do estado do Mato Grosso ${ }^{1}$. À época, vislumbrava-se na Educação a Distância o potencial da formação massiva, diante de um cenário de mais de cinco mil profissionais sem formação acadêmica, em um estado com grande 
dimensão geográfica. Passados 22 anos desde a oferta do primeiro curso de graduação a distância no país, o cenário não parece ser muito diferente. No entanto, atualmente configura-se o desenvolvimento da Educação on-line nas IES privadas ao passo em que ocorrem retrocessos nas IES públicas ${ }^{2}$. Em comparação à modalidade presencial, no entanto, a EaD a supera em termos de crescimento. De acordo aos dados do Instituto Nacional de Pesquisas Anísio Texeira - Inep, em comparação ao ensino presencial, de 2011 a 2015, houve aumento no número tanto de cursos e matrículas quanto de concluintes, na modalidade à distância ${ }^{3}$. Os dados do Inep revelam uma mudança de cultura no campo educacional que é reflexo também de uma sociedade globalizada, em rede. Daí a importância de aprofundarmos os estudos que contemplem esta nova cultura educacional permeada por novas linguagens e novos contextos.

\section{A EAD COMO PARADIGMA EDUCACIONAL}

O desenvolvimento da civilização (e de seus elementos culturais) está carregado de significados contextuais imprecindíveis para a inserção do indivíduo na sociedade. Sem o conhecimento dos significados dos artefatos, objetos, gestos, ações, expressões corporais, a fala etc, enfim, todos os elementos presentes numa determinada sociedade, não se poderão desenvolver boas formas de linguagem. Elementos culturais são carregados de significados, ou seja, signos. Eles são estudados à luz da semiótica social (SANTAELLA, 2003, p. 40). Mais recentemente observamos o desenvolvimento dos estudos à luz da filosofia da tecnologia, com métodos semelhantes à filosofia da ciência, através da observação empírica e conhecimento da causalidade natural. Diferenciam-se naturalmente nos objetivos. De acordo ao filósofo da tecnologia Andrew Feenberg, a ciência tem compromisso com a verdade, já a tecnologia, com a utilidade (FEENBERG, 2003눈. Dessa forma, a filosofia da tecnologia teria compromisso com a "ciência da utilidade" e, dessa forma, estabelece uma relação entre tecnologia e ética.

$\mathrm{Na}$ história do surgimento e desenvolvimento das universidades poderíamos dizer que esta instituição milenar passou por diversas revoluções e/ou quebras de paradigmas. Dentre esses períodos de transformação elencamos: a sua luta pela autonomia administrativa e liberdade científica e pedagógica (SANTOS e ALMEIDA FILHO, 2012); a ampliação do ensino superior após a segunda guerra muandial; o desenvolvimento das bibliotecas ligadas às universidades e o surgimento das tecnologias da informação e comunicação, criando uma série de possibilidades, desafios e rupturas (DIÓGENES e CUNHA, 2017). Na contemporaneidade, o grande desafio é a adaptação da ação pedagógica frente às novas linguagens produzidas no mundo moderno por meio das tecnologias da informação e comunicação, em suma, talvez o maior deles, a modalidade de Educação a Distância. 
Essa modadalidade traz consigo uma exigência, um maior rigor de defesa da autonomia tanto ao estudante quanto ao exercício pedagógico do docente. Nunca a pedagogia da autonomia de Freire se mostrou tão contundente. Sem autonomia o estudante de EaD não consegue cumprir seus objetivos com a qualidade requerida. Outra característica marcante da EaD é a intermediação realizada por meio das tecnologias da informação e comunicação, com vistas à interação e à interatividade. Na sua geração atual, a EaD é realizada basicamente por meio da internet, chamada por isso de Educação on-line. Esta só se realiza por meio de tecnologias educacionais digitais da internet. Certamente que a afiliação globalizada das tecnologias digitais, a simpatia e engajamento das redes sociais, integrando-as às práticas cotidianas, e a familiaridade das mesmas, impulsionou a propagação da Educação On-line.

Grande parte dos profissionais das universidades (ou instituições educacionais) que compõem as equipes ou núcleos de $\mathrm{EaD}$ são formados por profissionais com experiência prévia ou afinidade com tecnologias digitais. Nem sempre se trata de um fetiche pelo novo, pelo moderno e que encanta ou surpreende, mas sobretudo pela convicção de que as invenções do mundo moderno podem ser empregadas para benefício da educação. Nesse sentido, ocorre uma ruptura, uma oportuna quebra de paradigmas para a educação tradicional ao incorporar novos métodos. O papel do professor e do aluno precisam ser ressignificados por encontrarem-se deslocados do lugar de conforto da sala de aula presencial. A necessidade de o professor estar à frente para transmitir conhecimentos e simplemente tirar dúvidas se desfaz. A aprendizagem passa a ser realizada oportunamente a partir da construção do conhecimento já defendida pela pedagogia construtivista e sócio-interacionaista. Além do mais, a EaD é também uma fórmula em resposta a um mundo globalizado, que trouxe necessidades para o mundo do trabalho, de profissionais poli e multi facetados, criativos, que detém as informações e possuam conhecimentos atuais e compartilhados em rede.

Como se sabe, o surgimento da internet possibilitou a Educação On-line. A World Wide Webfoi criada, em 1969, em plena guerra fria, como uma alternativa de manter a comunicação de dados caso os meios convencionais de comunicação fossem destruídos ${ }^{5}$. Não obstante, a sua disseminação para domínio popular ocorreu no Brasil apenas em 1995. No entanto, antes desse acontecimento, algumas universidades públicas já a utilizavam em pesquisas para benefício da educação. A partir de então foi possível o seu uso na educaçãovisando ainteratividade e construção de conhecimentos.

\section{MOTIVAÇÃO PARA A PESQUISA}

Após terminar o meu curso de licenciatura, minha primeira experiência, e oportunidade 
como professor, foi na função de tutor de um curso de graduação à distância de uma faculdade privada, pioneira na oferta desta modalidade na Bahia. Posteriormente, ingressei no Instituto Anísio Teixeira - IAT, como Analista de Tecnologia Educacional, para trabalhar com cursos à distância, na área de formação de professores da rede estadual de ensino do Estado da Bahia. Neste Instituto, sentindo a necessidade da criação de um núcleo que contemplasse todas as ações em prol do desenvolvimento dos ambientes virtuais de aprendizagem - AVA, de forma colaborativa, escrevemos um projeto que unificavam as equipes pedagógica e técnica compondo uma comunidade multidisciplinar de aprendizagem, reunindo parte da equipe em mesmo espaço físico e parte dela em espaçovirtual (digital), visando a pesquisa e a inovação no gerenciamento de AVA. Este grupo foi denominado de Núcleo de pesquisas e Inovação dos Ambientes Virtuais de Aprendizagem - NIAVA (2013). Fui coordenador deste núcleo por cerca de dois anos e hoje coordeno um setor maior que engloba o mesmo núcleo. Desenvolvemos um novo ambiente que contemplou a resolução de parte das nossas inquietações em termos de design gráfico e desenho pedagógico, utilizando o sistema de gerenciamento de aprendizagem Moodle que, de acordo com pesquisas da Associação Brasileira de Educação a Distância, é utilizado pela grande maioria dos cursos superiores de educação a distância, seja de graduação ou pós-graduação (ABED, 2013).

O ambiente virtual de aprendizagem é indispensável para a educação on-line, pois é o principal espaço de mediação pedagógica. No entanto, várias são as fragilidades que podem ser identificadas no planejamento e execução de cursos para a educação online. Uma delas é a ausência de melhor domínio e estruturação dos softwares (SGA) que suportam os ambientes de aprendizagem (HAGUENAUER, 2012). Descreveremos a seguir alguns problemas decorrentes de configurações de interfaces dos ambientes virtuais.

\section{CATEGORIAS PROPOSTAS: ACESSO, PERMANÊNCIA E APRENDIZAGEM}

De forma correspondente à sala de aula física, toda sala de aula digital possui um meio de acesso, uma porta de entrada. Para se ter acesso a uma sala de aula em espaço físico não necessitamos de maiores protocolos ou permissões. Estando-se regularmente matriculado, a porta da sala de aula normalmente estará aberta para o estudante e para o professor. Caso seja o primeiro dia de aula e ele não saiba onde está sua sala, podese facilmente pedir ajuda a um funcionário da instituição ou a um transeunte. O mesmo não ocorre na educação à distância. Para acesso à sala de aula digital, ou ao ambiente virtual, cada estudante, ou mesmo o professor, necessita da chave da porta para acesso. Além do mais, ele deve procurar sozinho onde é o acesso no primeiro dia. No 
entanto, são recorrentes os problemas de acesso aos ambientes virtuais por dificuldades com a senha ou mesmo com a localização dos campos de usuário. Esse é um exemplo que evidenciam dificuldades para o aluno desde o primeiro acesso e, se recorridas vezes, impactam no seu objetivo principal que é a aprendizagem. Problemas com o acesso ao AVA podem ocasionar uma desmotivação precoce nos estudantes da EaD, contribuindo para as estatísticas da evasão.

Outro fator a se considerar é a permanência do estudante nos AVA. Mattar, no texto "Web 2.0 e Redes Sociais na Educação", aborda a resistência dos estudantes para com o AVA oficial da instituição em relação às redes sociais (MATTAR, 2013). Siemens e Weller (Apud MATTAR, 2013) afirmam que "Enquanto as universidades em geral lutam para ampliar a adoção de seus ambientes virtuais de aprendizagem, enfrentam o problema oposto com as redes sociais, pois não conseguem fazer com que os alunos parem de usá-las durante as aulas”. Dessa forma, um aspecto a ser investigado nesta pesquisa é a permanência do estudante no AVA. Os ambientes virtuais deverão concorrer com as redes sociais, tornar-se semelhante a elas, reinventarem-se?

Além do mais, questionamos o papel dos ambientes virtuais na aprendizagem. $\mathrm{Na}$ educação on-line o principal local onde se promove o encontro para a aprendizagem é o ambiente virtual, mas nem sempre as instituições preocupam-se com uma avaliação da aprendizagem que contemple estudos do design de interface. Um dos maiores educadoresdo século XX certa vez afirmou "A obra da educação é obra que pede 'Tempo limpo, céu claro, mar bonança”’ (TEIXEIRA, 1996). Longe de interpretá-la de maneira reducionista, mas reconhecendo a sua dimensão de significados, concordamos com o autor que um ambiente confuso, "tempestuoso" e desagradável não proporcionará uma aprendizagem significativa. Neste aspecto, ressaltamos o papel do design pedagógico de interface. Assim como estudamos o design de interface para peças de comunicação, defendemos o estudo das interfaces dos AVAs à luz da semiótica social.

\section{FUNDAMENTAÇÃO}

Pretende-se que estetrabalho contribua para pesquisadores, profissionais da educação, professores e estudantes da $\mathrm{EaD}$, de forma a avançarem no campo do planejamento de ambientes virtuais e melhor adaptá-los, prepará-los de forma crítica e significativa para o desenvolvimento dos processos de ensino-aprendizagem. Nesse aspecto, trata-se, portanto, de uma pesquisa aplicada (SILVA e MENEZES, 2005) que procura evidenciar através dos pressupostos da semiótica social e da multimodalidade, da teoria das affordances, como definições técnicas ou pedagógicas podem contribuir para problemas 
de percepção e construção de sentidos e, dessa forma, comprometer uma aprendizagem significativa.

Para o desenvolvimento teórico, buscou-se por meio da Semiótica Social, da multimodalidade e da teoria das affordances (DEELY, 1990; PINTO, 1995; SANTAELLA, 2003; NORMAN, 2006; VAN LEEUVWEN, 2005; KRESS, 2010), melhorauxílio para a compreensão da percepção e construção de sentidos, das linguagens e interações no meio digital e em ambientes virtuais de aprendizagem (CARVALHO, 2010, 2013; PAIVA, 2010; DIONISIO, 2011; SOUZA, 2011, 2013).

\section{CONCLUSÃO}

A inobservância de critérios contextuais, complexos adaptativos, têm sido desprezada a despeito de que os softwares se impõem com suas limitações técnicas ou formatações padronizadas. Acreditamos que grande parte dos problemas com affordances se dá pelo desconhecimento do domínio técnico na utilização das ferramentas, tanto por parte do aluno aprendente, quanto por parte do professor autor ou conteudista, quando não também pelo papel do design instructional ou desenvolvedor no trabalho de modelagem das salas/disciplinas ou mesmo pela ausência destes últimos profissionais. É necessário dar sentido a todas às funcionalidades propostas. Existem vários motivos pelos quais se criam resistências para o uso correto de ferramentas tecnológicas no auxílio ao trabalho de planejamento pedagógico de modelagem ou desenho dos cursos on-line. É necessário investigar ainda mais em que medida limitações para usos específicos (tomando-se como referência o Moodle) contribuem para problemas de significação nos ambientes virtuais de aprendizagem.

Propomos que as interfaces devam evitar atividades que foquem apenas a transmissão e o armazenamento de informação. Estas, conforme defende PAIVA (2010), proporcionam apenas a construção objetivista do conhecimento. Existem recursos potenciais para que os ambientes possam superar limitações técnicas, cumprindo o papel da construção de sentidos.Cabe investigar o tema de modo a construir-se metodologias que contribuam para a melhoria das affordances e da construção de sentidos nas salas virtuais.

\section{REFERÊNCIAS}

AFFORDANCE.WIKIPEDIA.Affordance. In: Affordance> Acessado em 02/06/2015

AUSUBEL, D.P. Psicología educativa: um punto de vista cognoscitivo. México: Editorial 
Trillas, 1976.

A Aprendizagem Significativa: a teoria de Ausubel. São Paulo: Moraes, 1982.

CARVALHO, Flaviane. Semiótica Social e Gramática Visual: o sistema de significados interativos. Revista Anglo Saxônica, Ser. III, N 1. Lisboa: Anglo Saxônica, 2010.

Temas Contemportâneos em Semiótica Visual. Brasília: CEPADIC, 2013.

DEELY, John. Semiótica básica. Trad. Julio Pinto. São Paulo: Ática, 1990.

DIONISIO, A. P. Gêneros Textuais e Multimodalidade. In: KARWOSKI, A. M.; GAYDECZKA, B.; BRITO, K. S. (Org.). Gêneros textuais: reflexões e ensino. São Paulo: Parábola Editorial, 2011.

Multimodalidade Discursiva na Atividade Oral e Escrita. In: MARCUSCHI, L. A. e DIONíSIO, A. P. (horas.). Fala e Escrita. Belo Horizonte: Autêntica, 2005.

EPSTEIN, Isaac. O Signo. 5a Edição. São Paulo: Ed. Ática, 1997.

GREENO, James. Gibson Affordance's. Psycological Review 1994. American Psichological Association, vol. 101, No 2, 1994.

HAGUENAUER, Cristina. Ambientes Virtuais na Web 2.0. Curitiba: EDITORA CRV, 2010.

HAGUENAUER, Cristina; CORDEIRO FILHO, Francisco. AMBIENTES VIRTUAIS DE APRENDIZAGEM: dos sistemas de gerenciamento aos games e à realidade virtual. Curitiba: EDITORA CRV, 2012.

KRESS, G. Multimodality: a social semiotic approach to contemporary communication. London/New York: Routledge, 2010.

KRESS, G; VAN LEEUWEN, T. Reading images: the Grammar of visual design. London: Routledge, 1996.

LEFFA, Vilson J. MARZARI, Gabriela Q. Design da página interativa na perspectiva da semiótica social. Linguagem em (Dis)curso, Tubarão, SC, v. 12, n. 2, p. 495-516, maio/ago. 2012. In: http://www.scielo.br/pdf/ld/v12n2/a06v12n2. Acesso em 05/03/2017. 
LÉVY, Pierre. O que é virtual? Trad. Paulo Neves. São Paulo, Ed. 34, 1996

MARTIN DOUGIAMAS. ; Moodle.udec.ntu-kpi.kiev.ua/martin_dougiamas.html>; ; Acessado em 10/05/2015.

MATTAR, João. Web 2.0 e redes Sociais na educação. São Paulo: Artesanato Educacional, 2013.

MOODLE. O que é Moodle? Moodle.org/29/en/Philosophy>; Moodle.org>. Acessado em 25/08/2014.

NORMAN, Donald A. Design do dia-a-dia. São Paulo: Rocco, 2006.

OLIVEIRA, José Renato G; NUNES, Maira M. Sobre A Autonomia Do Estudante Na Educação a Distância. Congresso Nacional de Ambientes Hipermídia para a Aprendizagem, 2011.

PAIVA, Vera M. de O. Ambientes Virtuais de Aprendizagem: implicações epistemológicas. Educação em Revista. Belo Horizonte, V.26, n.03, pp.353-370, dez. 2010.

PALLOFF, Rena M; PRATT, Keith. O Aluno Virtual: um guia para trabalhar com estudantes on-line. Porto Alegre: Artmed, 2004.

PELIZZARI, A; KRIEGL, M. L.; BARON, M.P; FINCK, N.T.L; DOROCINSKI, S.I. REV. Teoria da Aprendizagem Significativa. PEC, Curitiba, v.2, n.1, p.37-42, jul. 2001-jul. 2002.

PEIRCE, S. Charles. Escritos Coligidos. Coleção Os Pensadores. São Paulo: Abril Cultural, 1983.

Semiótica. Tradução de José Teixeira Neto. São Paulo: Perspectiva, 1977.

PINTO, J. Semiótica e Informação. Perspec. Ci. Inf., Belo Horizonte, v. 1, n. 1, p. 87-92, jan./jun, 1996.

PINTO, Júlio. 1,2 3 da Semiótica. Belo Horizonte: Ed. UFMG, 1995.

PRETTO, Nelson de Luca. Reflexões teório-metodologicas sobre ambientes virtuais de 
aprendizagem. Revista Debates em Educação, V1, N1, Jan/Jun, 2009. In: . Acessado em 15/12/2014.

SANTAELLA, Lúcia. Culturas e artes do pós-humano: da cultura das mídias à cibercultura. São Paulo: Paulus, 2003.

SANTAELLA, Lúcia. O que é semiótica? São Paulo: Brasiliense, 1983.

SOUZA, Valeska V. S. Virtual Learning Environments in the Light of the Complexity Paradigm: Interface, Affordances and Equifinality. RBLA, Belo Horizonte, v. 13, n. 2, p. 577-601, 2013.

DINAMICIDADE E ADAPTABILIDADE EM COMUNIDADES VIRTUAIS DE APRENDIZAGEM: UMA TEXTOGRAFIA À LUZ DO PARADIGMA DA COMPLEXIDADE. 2011. 256f. Tese de Doutorado - Universidade Federal de Minas Gerais - UFMG, Belo Horizonte, 2011.

VALENTINI, C. B.; SOARES, E. M. do S. Aprendizagem em Ambientes Virtuais: compartilhando ideias e construindo cenários. Caxias do Sul: Educs, 2010.

VAN LEEUWEN, T. Introducing a social semiotics.London: SAGE Publications Ltda., 2005.

VIEIRA, E; CUNHA, D; MARTINEZ, M. História da Educação A Distância no Brasil, Algumas Provocações. Revista Perspectivas em Políticas Públicas Belo Horizonte, Vol. IX, № 18, P. 121-148, jun/dez 2016.

ZUIN, A. S. A Vingança Do fetiche: Reflexões Sobre Indústria Cultural, Educação Pela Dureza E Vício. Educ. Soc., Campinas, vol. 27, n. 94, p. 71-90, jan./abr. 2006.

ZUIN, A. A. S. Cultura Digital, YouTube e Sadismo Pedagógico: novos avatares da relação entre professores e alunos. Congresso. Acessado em 12/08/16, In: http:/www.brasa.org/wordpress/Documents/BRASA_XII/Proceedings/Antonio\%20Zuin\% 20-\%20Cultura\%20Digital,\%20YouTube\%20e\%20Sadismo\%20Pedag\%C3\%B3gico.pdf

ZUIN, Antonio A. S. In: Educ. Soc., Campinas, v. 31, n. 112, p. 961-980, jul.-set. 2010. UFSCAR, 2010. Disponível em http://www.cedes.unicamp.br.

O plano nacional de educação e as tecnologias de informação e comunicação. 